\title{
The relationship between spatial awareness and mathematic disorders in elementary school students with learning mathematic disorder
}

\author{
Ahmad Yarmohammadian \\ University of Isfahan, Isfahan, Iran \\ Email address: \\ yarmo879@yahoo.com
}

To cite this article:

Ahmad Yarmohammadian. The Relationship between Spatial Awareness and Mathematic Disorders in Elementary School Students with Learning Mathematic Disorder. Psychology and Behavioral Sciences. Vol. 3, No. 1, 2014, pp. 33-40. doi: 10.11648/j.pbs.20140301.16

\begin{abstract}
This research was designed to study the relationship between spatial awareness with mathematic disorders, in elementary school students at grade three in Isfahan city. A sample of 60 students was selected from elementary schools. Spatial Awareness Questionnaire and Raven Intelligence Test were administered to the subjects. The results of stepwise regression analysis showed that the correlation between spatial awareness, IQ and classification of students with mathematic ability were significant $(\mathrm{P}<0.01)$. The results also showed that the correlation between gender and mathematic ability was not significant $(\mathrm{P}>0.05)$. The results of this study support the claim that stimulus of child in environment and pre-school programs especially in spatial awareness, can be progress mathematic ability of students in elementary school. The most important finding from these analyses is that mathematic performance relates with spatial awareness as well as intelligence.
\end{abstract}

Keywords: Spatial Awareness, Mathematic Disorders, Intelligence, Mathematic Ability

\section{Introduction}

Mathematics is a symbolic language which enables man to think about the quantity of the matters and to record them while they relate the thoughts and the relations between the quantities to each other. Nevertheless, a group of students with healthy senses and normal intellectual ability cannot learn the special educational matters and concepts by general methods in the schools (Oreyzi, Abedi, 2004). These students are considered as the students afflicted with learning disability because most of them with their potential ability make no progress in one course or in several courses. This disability includes a wide range of educational training (Delapaz \& Geraham, 1997). Among them, there is a group with mathematics disability that have difficulties in math. Diagnostic and Statistical Manual of Mental Disorders of America (2000) determined disable students in learning mathematics in this way: Disability in performing math skills, considering the intellectual capacity and the expected educational level of the person through some adjusted personal measured tests. Some of the Common clinical features of disable students in learning math are problems in learning the name of the numbers, counting the main numbers, coping the numbers, perceiving the analysis concepts and the combination of numbers, perceiving the meaning of the math signs or application of proper signs, perceiving the value of place and time, ordering the numbers in writing the problems, saving and ordering while computations. The expression used for severe cases is disorder in computing and perceiving mathematics concepts. This group of children usually faces some problems in perceiving the space relations (Seif Narghi, 2001). To explain the origin and the causes of this disability, some of the researchers indicate the problem of reading and language learning (Delapaz \& Graham, 1997). Some other researchers put the emphasis on the problems of counting and mathematic reasoning (Hoffman, 2003). Explaining the cause of disability in learning math: So far many studies are done and various opinions are stated by researchers including: considering some causes, such as neurology causes and weakness in cognitive and metacognitive skills (Montague, 1997), exciting causes, such as math anxiety (Lerner, 1993 quoted by Abedi, 2004) and computing problems (Fariar et al. 2001). One major factor which probably correlates with mathematic disorder is the spatial awareness or spatial 
relation. Spatial relation is the ability of seeing the relation of the forms and objects with each other. Also, spatial awareness is the ability to interpret spatial information and use it in an organized, systematic way for planning movement (Jenkinson, Hyde \& Ahmad, 2008).

In general, children's early mathematics ability is an important predictive factor to later math achievement (Aunio \& Niemivirta, 2010; Byrnes \& Wasik, 2009; Jordan et al., 2009; Krajewski \& Schneider, 2009), so the question of how to promote children's early math competency is of critical importance. Previous research has established a link between spatial ability and mathematics — both children and adults with better spatial abilities also have higher math scores (Burnett, Lane, \& Dratt, 1979; Casey et al., 2001; Casey et al., 1992; Casey et al.,1995; Delgado \& Prieto, 2004; Geary et al., 2000; Lubinski \& Benbow, 1992; Robinson et al.,1996) even in early childhood (Kyttälä et al., 2003, Geary et al., 2007; Rasmussan \& Bisanz, 2005; McKenzie et al., 2003; Mclean \& Hitch, 1999; Holmes et al., 2008; Alloway, 2007). Based on these findings, the National Council of Teachers of Mathematics (NCTM, 2010) announced its support of developing spatial reasoning as part of math learning in the first grade.

The connection between space and math may be based on shared underlying processes, suggesting a potent avenue for mathematical improvement(Cheng \& Mix, 2013). Neuropsychological and brain imaging studies have revealed that similar circuity is activated when people process both spatial and number tasks (Walsh, 2003; Hubbard et al., 2005). There also is behavioral evidence that numerical magnitudes are mentally represented in a spatial format (Dehaene, Bossini, \& Giraux, 1993). This evidence of shared mental processing raises the possibility that math can be improved with spatial training (Cheng \& Mix, 2011). Swanson(2003) states that the relation between spatial imagining abilities and spatial disorders is not computed in mathematics but the defect of the function of imagining affects various mathematics grounds, such as, geometry, and complex problem solving (quoted by Reisi, 2005). In fact, the children presenting lower mathematical function and ability in reading and spelling got higher scores in verbal-auditory scales and in visual-perceptive and lower scores in visual-spatial scales (Mash et al., 2003). In Sternberg's opinion, spatial ability points to the ability of decoding, transformation, and memorizing the pictures of the objects in space and their relations to other objects and the spatial successes (Poor-Mohsseni Clori, 2004, p.118). On the other hand, spatial awareness or perceiving spatial relation is really essential for success in mathematics, because the place value of the numbers. The order of the numbers, the perception of counting the objects in environment, reading them from left to right and the order of environmental objects are related to the perception of the spatial-place relations (quoted by Fariar et al., 2001), that this study tries to consider its relation to mathematical ability. This ability is related to the perception of the condition of the objects in space and place and is one of the dimensions of the visual functions, which ensures the perception of the displacement of an object or a symbol (pictures, letters and numbers) and its relation to far and close objects. Spatial perception ability is most probably related to the success in mathematics and geometry. Children with problems in the perception of lines and objects in space will probably have problems in recognition of the forms and geometrical plans. Some of the students' problems in spatial imagining act weakly in mathematics and computation. We found that even a short amount of spatial training can increase children's math performance. This result contributes to the growing literature that links spatial cognition to mathematical representation and problem solving, but is one of the only to demonstrate a causal link from one area to the other. Interestingly, the spatial training effect was most evident on missing term problems. Many studies have demonstrated that people who are better at spatial tasks also excel in mathematics(Cheng \& Mix, 2013).

Kalisky (1967) believes that most of the symptoms realized in the disabled children in learning can be related to the mathematical problems. Spatial perception disorder, visual perceptive disorders, unreasonable persistence, difficulty in understanding signs and cognitive disorders are all obvious numerical learning events.

The results of Pinel et Jerry's studies (1996) indicates that the defects of spatial imagining affects the function of various aspects of mathematics, such as, geometry and solving complex problems (quoted by Reisi, 2005). In a study, ability of spatial imagining for making images and manipulating information in learning and solving mathematical problems is essential (Reisi, 2005, p. 89). Hinchey and his colleagues (1999) found that the children with special defects in mathematical learning differ from each other on their estimating skills and their ability to solve complex problems. The function of these two skills is supported by spatial imagining (quoted by Reisi, 2005). Based on Kalisky's reports (1967) a child with a disability in mathematics often make mistakes in the perception of spatial relations, for example, they get confused in recognition, up- down, on- under, top-bottom, short-tall, far-close, front-behind, beginning-end, and middle and they combine them with each other.

Also the results obtained by Helland \& Asbjernsen(2003) showed that the spatial-visual disorders increase the mathematical problems in the children with Dyslexic. The results of Reisi's study (2005) showed that there is a significant difference between the spatial imagining the students with and without learning disability because the students who had a weak mathematical ability got lower scores in spatial imagining aspects. Moreover, the results of Frasting's test showed that the spatial imagining ability in the students without any special defect in learning mathematics was higher than that of students with special defects in learning mathematics.

Then, the connection between space and math is so compelling that many now believe spatial training could be 
an important resource for improving performance in Science, Technology, Engineering, and Mathematics (STEM) disciplines (Lubinski, 2010; Newcombe, 2010; Uttal et al., 2012). In fact, the National Council of Teachers of Mathematics (2010) now recommends integrating spatial reasoning into the elementary mathematics curriculum (quoted by Ganley et Al., 2011). Cheng and Mix (2013) found that spatial training group improved significantly on calculation problems. This result adds further support to claims that spatial cognition and mathematical reasoning are connected

The other important factor of success in mathematic is intelligence. Intelligence is one of the principles and essential discussions of psychology and many psychologists worked on its essence and measurement but so far they have achieved no explanations acceptable for all the researchers. Some ones consider it a public ability for adapting to new occasions, some others considerate the most essential factor of reasonable practical abilities, rational thinking and the effective reactions of the person with his environment. But what's important is that intelligence is a capacity and a higher ability for learning, act speeds, processing information, rational reaction to the affairs and events of life. In this study, the relation of intelligence as a control variable and the mathematical ability will be considered. Considering the description of the children with basic difficulties in mathematics, Johnson \& Myklebust (1967) concluded that these children face difficulty in non- verbal intellect's aspect.

Finally, spatial ability is required to understand mathematical symbols. Taken together, there is excellent reason to hypothesize that spatial training would improve math learning. The studies also show that sex differences do not always appear in these assignments. Also when these differences emerge, the rate of difference is low (Lehman, 2004, quoted by Reisi, 2005). In a research, Kaplan (1997) concluded that sex differences do not exist in spatial ability and this difference is ignorable. Though sex differences clearly appear in some spatial abilities, for example in some studies the spatial-visual talent of males is represented better and the privilege of females in verbal talents is indicated more than men, the results of most of the studies confirm no physical difference. The results of Reisi's studies (2005) showed that there is no meaningful difference between the spatial imagining of the male and females students of grade two in primary schools. The results of other research showed that spatial skill independently predicted a significant amount of the variability in concurrent mathematical performance (Verdine, Golinkoff, Hirsh-Pasek, Newcombe, Filipowicz and Chang, 2013). Because spatial and mathematical skills are vitally important for success in STEM careers and because spatial skills are foundational to mathematics learning, spatial instruction has become a priority in early education (NCTM, 2007).

According to what's said so far, the most essential matter discussed in this study is surveying the relation of spatial perception and mathematical disorders in the students of grade 3 in primary school. In fact, the present study tries to determine how much the rate of the influence of spatial awareness on mathematical ability is. Therefore, our primary aim was to investigate a potential causal relationship between spatial ability and math ability. With considering the discussions and findings of the present study, it answers the following questions:

1. How much is the share predicting spatial relations in mathematical ability?

2. How much is the share of intellect's predicting in mathematical ability?

3. Is the grouping variable considered as an essential predicting variable for the ability of mathematics?

4. Does sex have any influence on the ability of mathematics?

\section{Method}

\subsection{Statistical Society, Sample and Sampling Method}

The present study's plan is a predicting correlation. The aim of this method is predicting target variable among the other variable's scores. The statistical society of this study included all of primary school students of grade three in Isfahan city, among whom, 60 ones are chosen and are classified into two groups of weak and strong according to the average of class scores and their results in mathematic lesson. In selecting the participants, the sample group is selected randomly by using multistage cluster sampling. In selecting the samples, sex variable is controlled and for this aim the same number of sexes is chosen.

\subsection{Research Instruments}

Spatial Relation Perception Questionnaire (SPRQ) is used to evaluate spatial relations Perception. This questionnaire includes 70 phrases which are consisted of 5 scales or trivial tests (objects' recognition, object's features, the relations between objects and ordering) (Lacomb, 1996, translation \& adoption by Yarmohamadian, 2011). Every question has two options successful(2) or unsuccessful(0). Reliability co efficiency of this test obtained by split and Spearman- Brown formula is 0.98 . For the validity of the test, the content validity is used. Raven Intelligence Test(RIT) is used for evaluating general intelligence for the participants. This test was made by Raven in Britain in 1938 to measure general intelligence or factor $(\mathrm{g})$ spearman and revised in 1948. Test materials include 60 matrix and plans, a part of each of them was omitted and the person should find the omitted part among 6 or 8 options. Test questions were designed from simple to difficult. The test can be performed both individually and grouping. The test can be performed both on children and on mental retarded adults. The test is considered as a non-culture test (Farahani \& Farmihani, 2000). Each of the 60 questions of Raven's test has one score and no negative score is considered for wrong answers. The time of the performance of the test is 45 minitues. In the present study about validity co 
efficiency and reliability of Raven's test are reported. Coefficiencies close to $80 \%$ or a little more than $90 \%$ (Pasha Sharifi, 1995, P. 116-322).

\subsection{Statistical Methods}

Data are analyzed by (SPSS 16) software. The average of descriptive statistical criteria standard deviation, multiverbal Regression proving statistical criteria and analyzing variance of $\mathrm{F}$ are used for considering the results.

\section{Findings}

Table (1) represents descriptive statistic related to statistical variables, the average, standard deviation, minimum scores and the maximum of mathematical variables, spatial awareness and general intelligence.

Table 1. Descriptive statistic related to the studied variables

\begin{tabular}{llllll}
\hline Variable's name & N & Minimum & Maximum & Average & Standard deviation \\
\hline Mathematics & 60 & 4.5 & 20 & 11.81 & 4.48 \\
Spatial relations & 60 & 96 & 140 & 132.85 & 10.06 \\
Intelligence & 60 & 85 & 135 & 108.70 & 12.03 \\
\hline
\end{tabular}

Table 2. Correlation matrix of independent variable

\begin{tabular}{lllll}
\hline Factors & Mathematics & Spatial relations & Intelligence & Classification \\
\hline Mathematics & 1 & & & \\
Spatial relations & $* 0.502$ & 1 & 1 & \\
Intelligence & $* 0.984$ & $* 0.475$ & $* 0.650$ & 1 \\
Classification(weak \& strong & $* 0.671$ & $* 0.746$ & \\
groups) & &
\end{tabular}

$* \mathrm{P}<0.001$

Table (2) represents the internal correlation between studied variables as the information of these matrix represent there is a positive and meaningful correlation between all the studied subjects and mathematics.

To consider the effect of meaningful spatial awareness and intelligence on mathematical ability Regression's multi- variable method of analysis is used step by step. The results of the analysis are represented in table 3 and 4. According to table 3(ANOVA) The obtained $\mathrm{F}$ is meaningful up to $0 / 001$. This reveals that at least one of the independent variables is effective in predicting dependent variable, and the prediction is $99 \%$ meaningful.

Table 3. A brief analysis of variance in Regression's model of spatial awareness, intelligence, classification, and mathematical skills

\begin{tabular}{lllll}
\hline Criteria Source & Freedom degree & Derivations' average & F & Meaningful level \\
\hline \multirow{2}{*}{ Regression's remains } & 2 & 381.376 & 624 & 611.068 \\
\hline
\end{tabular}

Table 4. Regressions' results of the analysis of the relation between spatial awareness's causes, intellect, classification, and sex with mathematical skill.

\begin{tabular}{lllllcr}
\hline Criteria Causes & $\begin{array}{l}\text { Multi-correlation co } \\
\text { efficiency }\end{array}$ & $\begin{array}{l}\text { determinate } \\
\text { coefficient }\end{array}$ & t relation & b coefficient & $\begin{array}{l}\text { Error of } \\
\text { survey } \\
\text { criteria }\end{array}$ \\
\hline Spatial relations' perception & 0.502 & 0.252 & $* 3.577$ & -17.92 & 0.502 & 3.93 \\
Intelligence & 0.984 & 0.969 & $34.51^{* *}$ & -28.08 & 0.949 \\
Classification & 0.671 & 0.451 & $5.58^{*}$ & 1.60 & 0.799 & 0.671 \\
Sex & 0.272 & 0.074 & & 3.370 & 0.265 \\
\hline
\end{tabular}

$* \mathrm{P}<0.05 \quad * * \mathrm{P}<0.01$

The results of regression's analysis represented in table 4 reveals the relation between spatial relation perception intelligence, classification and sex. This amount is named multi-correlation co efficiency. As you see, intelligence has the most correlation with mathematical ability, after intelligence, successively the variable of spatial relation perception and classification in coefficient of determination are $25 \%$ and $45 \%$, representing mathematical ability $(\mathrm{P}<$ 0.05). But Regression's analysis showed no meaningful relation between sex and mathematical ability, meaning the sex has no role in predicting success in mathematical skills of the girls or the boys have similar ability in mathematics. 


\section{Discussions and Conclusion}

In this study the relation between spatial relation perception and mathematical disorders are considered. These results showed that spatial relation perception, intelligence and classification have a meaningful positive correlation with mathematical ability but the results didn't show any meaningful correlation between sex and mathematical ability. These results are in agreement with the results of the previous studies including (Johnson \& Myklebust, 1967; Kalisky 1967; Helland and Ajerson, 2003; Reisi, 2005; Ganley \& Vasilyeva, 2011; Verdine, Golinkoff, Hirsh-Pasek, Newcombe, Filipowicz, and Chang, 2013; Cheng \& Mix, 2013). The obtained results are analyzed as follow on the basis of study's questions:

The first question was determining the predicting share of spatial relation's perception about mathematical ability. The results of the study showed that spatial awareness or spatial relation perception (spatial imagining) has positive and meaningful correlation with mathematical ability, meaning that spatial awareness directly predicts mathematical ability, that is, the students with higher spatial awareness are more successful in mathematical ability and vice versa, those with lower spatial awareness are less successful in mathematical ability. In fact, among the components of mathematical ability many common factors can be found, such as, measurement perception, quantity, recognition of objects and etc. The relation between objects' distance and numerical computation which exist in both (Spatial relation perception and mathematical ability). The implicit results of this study is that preliminary program in pre-primary school level can indirectly develop the child perception from the spatial relations of the objects and environmental phenomena and then preliminaries make the child more successful in learning mathematics, considering the processing or learning problems of these children may block their learning routs, meaning that the teacher evaluate the students' motor skills, auditory memory, visual memory, perception of the stability of form, notice and perception before teaching mathematical concepts, and if he or she see any problem in this pre-educational skills, he or she should strengthen them, because some researchers consider this ability in learning mathematics (Faggiani and Faggiano, 2000; Plaza and Caldin, 1997).

The second question of this study was determining the predicting share of intelligence about the mathematical ability. The results of this study showed that intellect variable is an important item in predicting successes mathematical ability. The results of Wechsler' test by Reisi (2005) showed that there is a meaningful difference in learning mathematics the students with special learning difficulties and those without any special difficulty and the results of this study confirm the hypothesis of this research that there is a meaningful correlation between mathematical ability and intelligence. These results show that there are many common elements between intelligence and mathematical talent and ability which help the success of the person.
The third question of this study considers the relation between classification and mathematical ability in a way that the strong students are not only successful in mathematics but also in spatial awareness and general intelligence. The results which can be concluded from the study is that in teaching mathematics to children classifying them according to their ability level and taking educational methods, teaching suitable materials for these grouping, will increase their successes in learning mathematics. The results of this study and other studies confirm the results of the researches by (Swanson, 2003; Reizi, 2005; Oreizy and colleagues, 2004). As the results show that teaching and training in small groups can considerably be effective in teaching and progressing the children with mathematical learning disorder. They pointed out that classifying the disable children is as effective as teaching the standards individually (Allsop \& Medison, 2003; Bos and Vaughn, 2002; Oreizy et al., 2004).

The last question of this study considers the effects of the students' sex on mathematical ability. The results show that there was no meaningful relation between sex and mathematical ability variables. On the other word, sex no longer had any role in mathematical success and success in mathematics cannot merely be predicted on the basis of the individuals' sex. These results are in agreement with previous studies (Kaplan, 1997, Reisi, 2005, Lehman, 2004). The justification which can counted out here is that: Educational system can develop scientific skills of both sexes especially in mathematics.

In conclusion the present study confirms the existence of the relation between spatial relations, intelligence, grouping and mathematical ability by using spatial relation perception questionnaire and Raven intelligence test. The results also show that these variables predict success in mathematics and reveals that the students with higher rate of intelligence are more successful in mathematics than the other classmates. Also the results of this study confirm the results by Mash and Barkly (2003). Because the results are specified more generally as progress in mathematics is related to visual-spatial ability, visual perceptive abilities and other elements. For example, the researchers have understood the clear relation between mathematics progress and general intelligence and verbal ability. More over there are a lot of correlation between mathematical function and emotional features like attitude, interest and anxiety (Mash and Barkly, 2003).

Our findings, indicating a close relation between spatial skills and math outcomes in middle-school boys, suggest that even at this age, boys may be using spatial reasoning in solving mathematical tasks. The lack of a parallel relation in middle-school girls suggests that they do not rely on spatial skills as much as boys do in solving math problems. Thus, it becomes exceedingly important to focus the attention of educators both on the development of students' spatial skills and on facilitating their ability to apply spatial reasoning to problem solving across mathematical and scientific domains, which could benefit all students and girls in particular 
(Ganley and Mix, 2011). Among spatial skills, mental rotation ability in particular has been identified as a powerful predictor of students' math test scores (e.g., Casey, Nuttall, Pezaris \& Benbow, 1995; Reuhkala, 2001). One of the key cognitive factors implicated in math achievement is spatial reasoning (Ganley and Mix, 2011). Spatial skills are not only important in their own right but also because they are related to mathematical achievement (Clements \& Sarama, 2007; Robinson, Abbott, Berninger, \& Busse, 1996) and likely play a causal role in improving mathematical skills (Newcombe, 2010; Mix, Moore, \& Holcomb, 2011). Correlational studies confirm that spatial ability is related to math ability throughout development, including the early elementary grades. Research also indicates that quantities are represented in spatial formats (i.e., the mental number line and object files) beginning in early childhood and persisting into adulthood. All that said, it is not clear that spatial training would need to transfer to other spatial tasks to have an impact on math. There may well be productive connections between spatial training and math, even if these do not transfer to other spatial tasks, because the transfer could occur at a very specific process level. In fact, it is possible that certain spatial tasks are more similar to certain math tasks than they are similar to other spatial tasks if the same processes are engaged.

A recent study by Grissmer et al. (2013) provided experience to kindergarten and first-grade children with sets of visuospatial toy that required them to copy model designs. Although these activities were not specically mathematical in nature, they improved children's mathematical skills.

Another study by Cheng and Mix (2012) showed that training on a mental rotation task with 6- to 8-year-olds improved performance on calculation problems and the use of place value concepts. Kamii, Miyakawa and Kato (2004) also found that a range of skills that are both spatial and mathematical in nature appear to develop concurrently in children's block building. Furthermore, Gobel, Walsh and Rushworth (2001) found that similar areas in the brain respond when individuals engage in space and mathematics processing (see Umilt, Priftis, \& Zorzi, 2009, for a review). Thus, visual-spatial skills and mathematics, traditionally taught separately, regularly call on a shared set of foundational skills and may have a significant amount of overlap.

Based on the results and limitations of the this study, it is suggested that some other studies should be done on the different groups of the students, specially students with learning disorders, behavioral, emotional difficulties and mental retardation to ensure generalization of the results of this research. Further research is clearly needed to completely understand the nature of these effects - the critical variables that mediate these training effects and a full description of the links between specific spatial skills and specific math skills. However, the present findings are important because they provide at least an existence proof that spatial training can improve math performance.

\section{References}

[1] Abedi, Ahmad, (2004). Consideration and comparison of the effectivity of math teaching to the students with disorders in learning in Isfahan. Isfahan: Research council of Education.

[2] Alloway, T. P. (2007). Working memory, reading and mathematical skills in children with Developmental Coordination Disorder. Journal of Experimental Child Psychology, 96, 20-36.

[3] Alloway, T. P., \& Passolunghi, M. C. (2011). The relationship between working memory, IQ, and mathematical skills in children. Learning and Individual Differences, 21, 133-137.

[4] Allsop, P. D. \& Medison, J. (2003). Unlocking math learning problems: Teaching mathematics to students with learning problems, http: //ttac: cisat. Jmu.edu.

[5] American Psychiatric Association. (2000). Diagnostic and Statistical Manual of Mental Disorders. Washington, DC: Author.

[6] Aunio, P., \& Niemivirta, M. (2010). Predicting children's mathematical performance in grade one by early numeracy. Learning and Individual Difference, 20, 427-435.

[7] Bos, C. S. \& Vaughn, S. (2002). Strategies for teaching students with learning and behavior problems, ( $5^{\text {th }} \mathrm{Ed}$.). Boston: Allyn and Bacom.

[8] Burnett, S. A., Lane, D. M., \& Dratt, L. M. (1979). Spatial visualization and sex differences in quantitative ability. Intelligence, 3, 345-354.

[9] Byrnes, J. P., \& Wasik, B. A. (2009). Factors predictive of mathematics achievement in kindergarten, first and third grades: An opportunity-propensity analysis: An opportunity-propensity analysis. Contemporary Educational Psychology, 34, 167-183.

[10] Casey, M. B., Nuttall, R. L., \& Pezaris, E. (2001). Spatialmechanical reasoning skills versus mathematical self confidence as mediators of gender differences on mathematics subtests using cross-national gender-based items. Journal for Research in Mathematics Education, 32, $28-57$.

[11] Casey, M. B., Nuttall, R. L., Pezaris, E., \& Benbow, C. P. (1995). The influence of spatial ability on gender differences in math college entrance test scores across diverse samples. Developmental Psychology, 31, 697-705.

[12] Casey, M. B., Nuttall, R., Pezaris, E., \& Benbow, C. (1995). The influence of spatial ability on gender differences in mathematics college entrance test scores across diverse samples. Developmental Psychology, 31(4), 697-705. doi:10.1037/0012-1649.31.4.697.

[13] Casey, M. B., Pezaris, E., \& Nuttall, R. L. (1992). Spatial ability as a predictor of math achievement: The importance of sex and handedness patterns. Neuropsychologia, 30, 3545.

[14] Cheng, Y. L., \& Mix, K. S. (2012). Spatial training improves children's mathematics ability. Journal of Cognition and Development, doi:10.1080/15248372.2012.725186 
[15] Cheng, Yi-Ling \& Mix, Kelly S. (2013). Spatial training improves children's mathematics ability. Journal of cognition and development. http://dx.doi.org/10.1080/15248372.2012.725186

[16] Clements, D. H., \& Sarama, J. (2007). Effects of a preschool mathematics curriculum: Summative research of the Building Blocks project. Journal of Research in Mathematics Education, 38, 136-163. doi: $10.2307 / 30034954$

[17] Dehaene, S., Bossini, S., \& Giraux, P. (1993). The mental representation of parity and number magnitude. Journal of Experimental Psychology: General, 122, 371-396.

[18] Delapaz. S. \& Graham, S. (1997) .Strategy instruction in planning, Effect on the Writing Performance and Behavior of Students With learning Disabilities, Exceptional children, Vol 63, 167-181.

[19] Delgado, A. R., \& Prieto, G. (2004). Cognitive mediators and sex-related differences in mathematics. Intelligence, 32(1), 25-32.

[20] Diagnostic and Statistical Manual of Mental Disorders of America. (1994). U.S Psychology Council, translated by Mohamad Reza Nainian, Alahyary, Abasali, Madahi, Mohamad Ebrahim (1995). Tehran: Shahed publication.

[21] Faggiano, L. \& Faggiano, E. (2000). Math cooperative Learning with Networking Technology.WWW. tidemark. cu.

[22] Fariar, Akbar; Rakhshan, Fereidoun, (2001). learning disorders. Tabriz: Nia publication.

[23] Farmihani Farahani, Mohsen. (2000). Scientific descriptive encyclopedia. Tehran: Asrar Danesh publication.

[24] Ganley, Colleen M. \& Vasilyeva, Marina. (2011). Sex differences in the relation between math performance, spatial skills and attitudes. Journal of applied developmental psychology, 32, 235-242.

[25] Geary, D. C. (1993). Mathematical disabilities: Cognitive, neuropsychological, and genetic components. Psychological Bulletin, 114, 345-362.

[26] Geary, D. C., Hoard, M. K., Byrd-Craven, J., Nugent, L., \& Numtee, C. (2007). Cognitive mechanisms underlying achievement deficits in children with mathematical learning disability. Child Development, 78, 1343-1359.

[27] Geary, D. C., Hoard, M. K., Byrd-Craven, J., Nugent, L., \& Numtee, C. (2007). Cognitive mechanisms underlying achievement deficits in children with mathematical learning disability. Child Development, 78, 1343-1359.

[28] Geary, D. C., Saults, S. J., Liu, F., \& Hoard, M. K. (2000). Sex differences in spatial cognition, computational fluency, and arithmetic reasoning. Journal of Experimental Child Psychology, 77(4), 337-358. doi:10.1006/jecp. 2000.2594.

[29] Grissmer, D. W., Mashburn, A. J., Cottone, E., Chen, W. B., Brock, L. L., Murrah, W. M., et al. (2013, April). Play-based after-school curriculum improves measures of executive function, visuospatial and math skills and classroom behavior for high risk K-1 children. Paper presentedat the Society for Research in Child Development, Seattle, WA.

[30] Helland T.; Asbjernsen A. (2003). Visual-Sequential and Visio-Spatial Skills in Dyslexia: Variations According to
Language Comprehension and Mathematics Skills. Child Neuropsychology (Neuropsychology, Development and Cognition: Section, vol. 9, no. 3, pp. 208-220.

[31] Hoffman, A. (2003). Teaching Decision Making to student with Learning Disabilities by Promoting self- Determination, wwww.eric. edu. Gov.

[32] Holmes, J., Adams, J. W., \& Hamilton, C. J. (2008). The relationship between visuospatial sketchpad capacity and children's mathematical skills. European Journal of Cognitive Psychology, 20, 272-289.

[33] Hubbard, E. M., Piazza, M., Pinel, P., \& Dehaene, S. (2005). Interactions between number and space in parietal cortex. Nature Reviews Neuroscience, 6, 435-448.

[34] Jenkinson, J., Hyde, T. \& Ahmad, S. (2008). Building blocks for learning occupational therapy approaches. First edition, Wiley-Blackwell.

[35] Johnson, D. and Myklebust, H. (1967). Learning disabilities: Educational Principles and practices. New York: Grune \& Stratton.

[36] Jordan, N. C., Kaplan, D., Ramineni, C., \& Locuniak, M. N. (2009). Early math matters: Kindergarten number competence and later mathematics outcomes. Developmental Psychology, 45, 850-867.

[37] Kaliski, L. (1967). Arithmetic and the brain-injured child. pp 458-466 in Edward Frierson and Walter Barbe (Eds.). Educating children with learning disabilities, Selected Readings. New York: Appelton-century Crofts.

[38] Kamii, C., Miyakawa, Y., \& Kato, Y. (2004). The development of logico-mathematical knowledge in a blockbuilding activity at ages 1-4. Journal of Research in Childhood Education, 19, 44-57. doi:10.1080/0256854 0409595053

[39] Kaplan, Harold; Saduke, Beniamin, (1994). Behaviorclinical psychology sciences' summary. PoorAfkary, Nosratolah, third edition, Tehran: Shahre Aab publication.

[40] Kaplan, P. J. (1997). Gender differences in spatial abilities exist? American Psychologist, PP. 776 - 799.

[41] Krajewski, K. \& Schneider, W. (2009). Early development of quantity to number-word linkage as a precursor of mathematical school achievement and mathematical difficulties: Findings from a four-year longitudinal study. Learning and Instruction, 19(6), 513-526.

[42] Kytta"la", M., Aunio, P., Lehto, J. E., Van Luit, J., \& Hautamaki, J. (2003). Visuospatial working memory and early numeracy. Educational and Child Psychology, 20, 6576.

[43] Lehman, W. (2004). The Relationship between spatialal abilities and representations, P.P. 95- 107.

[44] Lubinski, D. (2010). Spatial ability and STEM: A sleeping giant for talent identification and development. Personality and Individual Differences, 49, 344-351.

[45] Lubinski, D., \& Benbow, C. P. (1992). Gender differences in abilities and preferences among the gifted: Implications for the math=science pipeline. Current Directions in Psychological Science, 1, 61-66. 
[46] Mash , Eric, Jay, and Barkly, Rasel. A. (2003). Child Psychopathology. Section 2. Translated by Tuzande Jani, Hassan; Tavakoli-Zadeh, Jahanshir and Kamalpoor, Nasrin. (2004). Tehran: Marandiz edition.

[47] McKenzie, B., Bull, R., \& Gray, C. (2003). The effects of phonological and visual-spatial interference on children's arithmetical performance. Educational and Child Psychology, 20, 93-108.

[48] McLean, J. F., \& Hitch, G. J. (1999). Working memory impairments in children with specific arithmetic learning difficulties. Journal of Experimental Child Psychology, 74, 240-260.

[49] Mix, K. S., \& Cheng, Y.-L. (2012). Space and math: The developmental and educational implications. In J. Benson (Ed.), Advances in child development and behavior (pp. 179-243). New York, NY: Elsevier.

[50] Mix, K. S., Moore, J. A., \& Holcomb, E. (2011). One-toone play promotes numerical equivalence concepts. Journal of Cognition and Development, 12, 463-480. doi:10.1080/15248372.2011.554928

[51] Montague, M. (1997). "Cognitive Strategy Instruction in Mathematics for Student whit Learning Disabilities " Journal of Disabilities, vol, 30(2), PP 164.177

[52] National Council of Teachers of Mathematics (NCTM). (2007). Second handbook of research on mathematics teaching and learning. Washington, DC: National Council of Teachers of Mathematics.

[53] National Council of Teachers of Mathematics. (2010). Focus in Grade 1: Teaching with curriculum focal points. Reston, VA: Author.

[54] Newcombe, N. S. (2010). Picture this: Increasing math and science learning by improving spatial thinking. American Educator, 34, 29-35.

[55] Newcombe, N. S. (2010). Picture this: Increasing math and science learning by improving spatial thinking. American Educator, 29-43.

[56] Oreizy, Hamid Reza, Abedi, Ahmad, (2004). Consideration and comparison of the effectivity of math teaching techniques to students with learning disorders in learning. Innovation educational syllabuses, 8nom, third year. P. 9479.

[57] Pasha Sharifi, Hassan. (1995). Principals of psychometric and psychometric. Tehran: Roshd publication.

[58] Plaza, M. Claudine, G. (1997). Working Memory Limitation, Phonological Deficit, Sequential Disorder in a child with Dyslexia" dyslexia, vol. 3.
[59] Poor-Mohsseni Kloori, Fereshte. (2004). considering computer games on SHENAKHTI skill of teenagers, M.A thesis, Tarbiat Modares university.

[60] Rasmussen, C., \& Bisanz, J. (2005). Representation and working memory in early arithmetic. Journal of Experimental Child Psychology, 91, 137-157.

[61] Reisi, Maryam, (2005). Consideration and comparison of spatial imagination of the students' with or without special disorder in learning basic mathematics, grade two in Isfahan in 2005-2006. M.A thesis of Psychology and Scientific faculty of Alameh Tabatabi University.

[62] Reuhkala, M. (2001). Mathematical skills in ninth-graders: Relationship with visuospatial abilities and working memory. Journal of Educational Psychology, 21(4), 387-399. doi:10.1080/01443410120090786.

[63] Robinson, N. M., Abbott, R. D., Berninger, V. W., \& Busse, J. (1996). The structure of abilities in math-precocious young children: Gender similarities and differences. Journal of Educational Psychology, 88, 341-352. doi:10.1037//0022-0663.88.2.341

[64] Seif Naragi, Maryam and Naderi, Ezatolah, (2001). Special disorders in learning. Tehran : Macyal publication.

[65] Swanson, H. L., Harris, K. P. \& Graham, S. (2003). Handbook of learning disabilities. New York: Guilford.

[66] Troia, G. A; Graham, S., \& Harris, K. R. (1999). Teaching students with learning disabilities to mindfully plan when writing, Exceptional children, Vol. 65, 235-253.

[67] Umilta', C., Priftis, K., \& Zorzi, M. (2009). The spatial representation of numbers: Evidence from neglect and pseudoneglect. Experimental Brain Research, 192, 561-569.

[68] Uttal, D. H., Meadow, N. G., Tipton, E., Hand, L. L., Alden, A. R., Warren, C., et al. (2013). The malleability of spatial skills: A meta-analysis of training studies. Psychological Bulletin, 139, 352-402. doi:10.1037/a0028446

[69] Verdine, Brian N., Golinkoff, Roberta M., Hirsh-Pasek, Kathryn, Newcombe, Nora S., Filipowicz, Andrew T. and Chang, Alicia. (2013). Deconstructing Building Blocks: Preschoolers' Spatial Assembly Performance Relates to Early Mathematical Skills. Child Development, xxxx 2013, Volume 00, Number 0, Pages 1-14.

[70] Walsh, V. (2003) A theory of magnitude: common cortical metrics of time, space and quantity. Trends in Cognitive Sciences, 7, 483-488.

[71] Yarmohamadian, Ahmad. (2012). Psychomotor disorders and rehabilitation. First edition, Isfahan: published in University of Isfahan. 